Научная статья

УДК 811.512 .375

DOI: $10.18101 / 2305-459 X-2020-3-51-62$

\title{
АРХИВНЫЕ МАТЕРИАЛЫ И ПРОБЛЕМЫ КАЛМЫЦКОГО ЯЗЫКОЗНАНИЯ
}

\section{(C) Сусеева Данара Аксеновна}

доктор филологических наук, профессор, профессор кафедры русского языка и общего языкознания и русской и зарубежной литературы, Калмыцкий государственный университет им. Б. Б. Городовикова Россия, 358000, г. Элиста, ул. Пушкина, 11 suseeva@gmail.com

Аннотация. Большую помощь современному исследователю-калмыковеду могут оказать материалы, хранящиеся в Бюджетном учреждении Республики Калмыкия «Национальный архив». Тысячи деловых писем калмыцких ханов XVIII в. и их современников донесли до нас не только конкретные исторические события, но и культурную (понятийную) картину мира калмыцкого народа, которая была сформирована на основе конкретных людей, полученных с помощью их органов чувств и прошедших через их сознание, как коллективное, так и индивидуальное. Эти архивные материалы свидетельствуют о том, что культурная картина мира калмыцкого народа богата и своеобразна. Это своеобразие связано с целым рядом фактов, а именно: с кочевым образом жизни народа, культурой, историей, социальным устройством общества, религией, традициями, обычаями в новых социальноисторических условиях. Изучая мир калмыков XVII-XVIII вв., их культуру, образ жизни, национальный характер, менталитет, можно познать особенности калмыцкого языка, потому что реальное употребление калмыцких слов в речи, реальная калмыцкая речевая деятельность (или речепроизводство) в значительной степени определяются социальной и культурной жизнью говорящего на калмыцком языке - языке калмыцкого народа, живущего в составе Российского государства более 400 лет. В основе калмыцких языковых структур лежат не только структуры социокультурные, но и речевые. Знать значения калмыцких слов и правила калмыцкой грамматики недостаточно для того, чтобы пользоваться языком как средством общения, делая это общение эффективным, результативным. Необходимо глубже знать мир изучаемого языка. Исследуя речевую деятельность, надо обращать внимание на то, кто, когда, где, кому, что сказал/написал, как сказанное/написание содержание (информация) соответствует реальности, в которой осуществляется общение. Язык деловой переписки калмыцких ханов и их современников дает ответы на многие проблемные вопросы калмыцкого языкознания и, в частности, калмыцкой лексикографии.

Ключевые слова: калмыцкий язык XVIII в.; материал, методология и методы исследования; архивные документы как основа для решения актуальных проблем калмыцкого языкознания и исторической лексикографии.

\section{Для цитирования}

Сусеева Д. А. Архивные материалы и проблемы калмыцкого языкознания // Вестник Бурятского государственного университета. Язык. Литература. Культура. 2020. Вып. 3. С. 51-62. 


\section{Введение}

Калмыцкое языкознание существует более двухсот лет. Начало калмыцкому языкознанию положили А. А. Бобровников и А. Попов, авторы первых грамматик калмыцкого языка. Заметный вклад в развитие калмыцкого языкознания внесли ученые XX-XXI вв.: Б. Я. Владимирцов, Г. И. Рамстедт, Вл. Л. Котвич, Г. Д. Санжеев, Б. Х. Тодаева, Ц. Д. Номинханов, Д. А. Павлов, И. К. Илишкин, Б. Б. Бадмаев, У. У. Очиров, Б. Д. Муниев, А. Ш. Кичиков, Г. Ц. Пюрбеев, Э. Ч. Бардаев, П. Ц. Биткеев, Р. П. Харчевникова, Б. Б. Манджикова, А. Л. Каляев, М. У. Монраев, В. Э. Очир-Гаряев, Н. Н. Убушаев, В. Н. Мушаев, Э. У. Омакаева, Е. В. Бембеев и др.

Усилиями калмыцких ученых созданы первый словарь современного калмыцкого языка [12] и первая нормативная грамматика современного калмыцкого языка [Грамматика калмыцкого языка 1983], Б. Б. Бадмаевым и У. У. Очировым - первые школьные учебники современного калмыцкого языка и т. д. Однако многие важные вопросы калмыцкого языкознания до настоящего времени не решены. К числу сдерживающих факторов следует отнести отсутствие единства в использовании лингвистической терминологии, непонимание истории калмыцкого языка и ее значения для построения грамматики современного калмыцкого языка.

\section{Методы исследования}

Статья посвящена актуальному вопросу — решению наиболее важных проблем калмыцкого языкознания. К их числу относятся: современная языковая ситуация в Калмыкии, современное состояние калмыцкого языка и история калмыцкого языка. Решение этих проблем - это не только ключ к пониманию и проведению научно обоснованной языковой политики в Калмыкии, но и ключ к научному пониманию современного состояния и истории калмыцкого языка. Языковая ситуация в Калмыкии - следствие исторического развития калмыцкого народа в составе Российского государства. Калмыцкий язык «обслуживает» калмыцкий народ на протяжении четырех столетий в новых исторических условиях, на новой территории, в новых географических условиях и в новой социально-культурной среде, отражает в себе реальность прошедших времен. Зная историю калмыцкого языка, можно решить многие проблемные вопросы современного калмыцкого языкознания, в том числе и проблемы лексикографии.

Автор поставил цель - разработать новый подход в деле изучения современного калмыцкого языка с учетом истории языка на материале документов XVIII в., которые хранятся в Бюджетном учреждении Республики Калмыкия «Национальный архив» (сокращенно - БУ РКНА). Такой подход требует решения четырех задач: а) полное выявление и изучение памятников калмыцкого языка XVIII в.; б) публикация текстов этих документов с их переводами и комментариями; в) создание грамматики калмыцкого языка XVIII в. и г) создание словаря XVIII в. В процессе изучения истории калмыцкого языка необходимо использовать достижения современного теоретического языкознания. В методологическом аспекте необходимо придерживаться разграничения языка и речи, синхронии и диахронии, статики и динамики; учитывать связь языка и мышле- 
ния, языка и общества. Изучая язык памятников XVIII в., необходимо использовать не только традиционные методы (описательный, сравнительный и историкосравнительный), но и новые, например основы теории и принципы филологического анализа текста.

\section{Результаты исследования}

Получены первые результаты такого подхода: нами изучено около двух тысяч официально-деловых документов XVIII в. На их основе подготовлены к публикации и изданы официально-деловые письма хана Аюки [8], ханов ЧеренДондука, Дондук Омбо, Дондук Даши, написана первая грамматика калмыцкого языка XVIII в. [9]. Проделанная работа позволила нам приблизиться к решению четвертой задачи, связанной с созданием словаря калмыцкого языка XVIII в. Этот этап авторского подхода, а именно: создание нового словаря калмыцкого языка XVIII в., открывает новое направление - сопоставление лексики калмыцкого языка с лексикой монгольских языков XVIII в. на новом материале, ранее неизвестном науке.

\section{Обсуждение результатов}

Калмыцкое общество и калмыцкий народ развиваются вместе, а вместе с ними и калмыцкий язык. Знания о калмыцком языке, полученные в XIX-XX вв., уже недостаточны для того, чтобы калмыцкое языкознание развивалось успешно дальше. Современный уровень общественного развития предъявляет новые требования к научному осмыслению и решению ряда важных вопросов, без которых невозможно принимать решения о калмыцком языке. К их числу относятся такие вопросы, как языковая ситуация в Республике Калмыкия и перспективы дальнейшего ее развития, современное состояние калмыцкого языка (место и роль родного языка в жизни общества), история калмыцкого языка, создание научной грамматики в качестве базы для всех типов грамматик (вузовской, школьной, нормативной, коммуникативной, когнитивной и др.).

Большую помощь в деле решения актуальных проблем калмыцкого языкознания могут оказать материалы, отложившиеся в «Национальном архиве» Республики Калмыкия. Тысячи деловых писем калмыцких ханов XVIII в. донесли до нашего времени не только конкретные исторические события, но и культурную (понятийную) картину мира калмыцкого народа. Эти архивные материалы свидетельствуют о том, что культурная картина мира калмыцкого народа богата и своеобразна. Это своеобразие связано с целым рядом факторов, а именно: с проявлением в новых социально-исторических условиях форм кочевого образа жизни народа, культуры, традиций, обычаев, религии и т. д. Изучая мир калмыков XVII-XVIII вв., можно познать особенности калмыцкого языка, потому что реальное употребление калмыцких слов в речи, реальная калмыцкая речевая деятельность (или речепроизводство) в значительной степени определяется социальной и культурной жизнью говорящего на калмыцком языке - языке калмыцкого народа, живущего в составе Российского государства на протяжении нескольких столетий. В основе калмыцких языковых структур лежат структуры как социокультурные и лингвистические, так и ситуативно-временные. Знать значе- 
ния калмыцких слов и правила калмыцкой грамматики недостаточно для того, чтобы пользоваться языком как средством общения, делая это общение эффективным, результативным. Необходимо, как известно, глубже знать не только культурный мир и язык изучаемого народа, но и индивидуальный мир и речь отдельного человека. Исследуя речевую деятельность человека, надо обращать внимание на то, кто, когда, где, кому, почему и зачем, что сказал/написал, как сказанное/написанное содержание (информация) соответствует реальности, в которой осуществляется общение. Язык деловой переписки калмыцких ханов и их современников дает ответы на многие проблемные вопросы калмыцкого языкознания и, в частности, калмыцкой лексикографии.

В процессе формирования национального калмыцкого литературного языка XVIII в. является важным этапом. К этому времени в междуречье Дона, Волги и Урала в основном завершилось формирование новой народности ойратского происхождения - калмыцкой, а также Калмыцкого ханства в составе Российского государства. Калмыцкая народность формируется в принципиально новых условиях территориальных, экономических, культурных, исторических, то есть отличных от тех условий, в которых продолжали оставаться и развиваться остальные объединения ойратского (и шире - монгольского) происхождения. Век восемнадцатый - далеко не простой этап в развитии калмыцкого языка, который в это время характеризуется изменениями в языковой системе на всех его ярусах: фонологическом, морфемном, словообразовательном, лексическом, морфологическом и синтаксическом. Эти изменения способствуют складыванию единых норм калмыцкого литературного языка в письменной и устноразговорной формах. Калмыцкий литературный язык, судя по его официальноделовому стилю, впитывал в себя все лучшее, что было в языке калмыков. Деловая переписка калмыцких владельцев с представителями властей всех уровней Российского государства представляет собой богатейший, бесценный источник для изучения лексики калмыцкого языка XVIII в. К сожалению, тексты этих документов, отражающие историю, культуру, экономику калмыцкого народа, еще не попали в число важных источников по истории калмыцкого языка. Пока имеется один опыт составления исторического словаря на материале языка деловой переписки хана Аюки [8, с. 327-369]. А как известно, без исторического словаря невозможно представить все богатство современного калмыцкого литературного языка, выявить процессы, которые происходили в языке, как происходил отбор лексических средств на разных этапах формирования норм калмыцкого литературного языка и т. д.

В калмыцком языкознании в последние два десятилетия активизировалась работа по изучению языка деловой переписки калмыцких ханов и их современников. Исследователи осознают, что результаты изучения архивных материалов, хранящихся в БУ РКНА, являются надежной базой для решения многих архиважных вопросов. К их числу относятся, например, изучение принципов организации языковой системы калмыцкого языка на всех его уровнях, а именно: фонологическом, лексическом, морфологическом и синтаксическом. Архивные материалы помогают раскрыть жанровое многообразие официально-деловой письменности; наконец, открывают возможность сравнения таких стилей калмыцкого 
литературного языка, как официально-деловой, художественный и обиходноразговорный. Калмыцкий язык XVIII в. изучался Д. А. Сусеевой [8; 9; 10 и др.], Д. Б. Гедеевой [3], Н. О. Кокшаевой [4], А. Т. Хараевой [11]; защищена кандидатская диссертация по языку деловых писем хана Церен-Дондука Н. Д. Асировой [1]. Однако в грамматическом и лексическом плане этот архивный материал изучен недостаточно.

Между тем изучение языка деловых документов, написанных на тодо бичиг, хранящихся в БУ РКНА, весьма перспективно для разработки таких направлений истории калмыцкого языка, как, например, историческая фонология, историческая морфемика, историческое словообразование, историческая лексикология, историческая морфология, исторический синтаксис, историческая диалектология и т. д. Результаты изучения языка деловых документов, наконец, помогут более доказательно проводить различие между литературным калмыцким языком XVIII в. и калмыцкими переводами религиозных текстов (тибетского и санскритского происхождения) того времени, то есть помогут не отождествлять два разных понятия: калмыцкий литературный язык и язык переводов религиозных текстов.

С исследованием языка деловых документов XVIII в. открывается возможность изучения лексического состава калмыцкого языка конкретного времени времени формирования Калмыцкого ханства в составе Российского государства. Появляется уникальный языковой материал для описания парадигматических, синтагматических и словообразовательных связей конкретных слов, для раскрытия причин освоения заимствованной иностранной лексики и их адаптации в конкретную эпоху в калмыцком языке. Создается надежная база для сбора лексического материала и составления исторического словаря калмыцкого языка XVIII в., который наглядно продемонстрирует не только общие черты с монгольскими языками, но и отличные, уникальные, специфические, появившиеся в связи с вхождением калмыков в состав Российского государства. Деловые документы XVIII в. в качестве лексикографического источника обладают, без сомнения, уникальным содержанием, определенной исторической, социологической и культурной информативностью, которые в ходе исследования этих документов обеспечат объективность лингвистической информативности.

В XVIII в. Россия окончательно сформировалась как единое многонациональное государство, составной частью которого стало Калмыцкое ханство. В 2009 г. Калмыкия отметила как всенародный праздник юбилейную дату 400-летие своего добровольного вхождения в состав России. В БУ РКНА хранится обширная деловая переписка калмыцких ханов XVIII в. и их современников с представителями разных уровней и ветвей российской власти. Письма адресовались боярам, воеводам, комендантам городов Поволжья, Дона и Кавказа, а также губернаторам, министрам и царям (императорам). Тысячи официально-деловых писем калмыцких ханов и их современников, написанных на старописьменном калмыцком языке, отражают деятельное участие калмыков в социальноэкономической, военной, политической и международной сферах в составе Российского государства. К примеру, письма калмыцких владельцев в адрес российских властей ценны тем, что они несут в себе богатейшую информацию об уча- 
стии калмыков во всех важных событиях России XVIII в., которые связаны с укреплением ее как великой державы [6, с. 151-162]. Эти письма, отложившиеся в БУ РКНА, подтверждают, что калмыцкие войска были посланы Петру Первому под Полтаву (1709 г.), участвовали в Северной войне (1700-1721 гг.), Персидском походе (1722-1723 гг.), русско-турецкой войне (1733-1738 гг.), Семилетней войне (1758-1762 гг.) и др. [8, с. 74-78]. Этим объясняется то, что в языке деловых писем калмыцких ханов и владельцев XVIII в. имеется значительное число русских заимствованных слов, не имеющих аналогов в родственных монгольских языках того времени. Заимствования из русского языка обозначали: 1) воинские звания: салдат «солдат», апищеер «офицер», енерал «генерал», пельд маршал «фельдмаршал», кибатани «капитан», булгаадар «бригадир» и др.; 2) русские собственные имена исторических лиц: Петр Матвеевич Апраксин, Михаил Михайлович Голицин, Василий Никитич Татищев, Никита Афанасьевич Бекетов и др.; 3) названия стран, где бывали калмыки: Нумеш «Германия», Xaрам «Крымское ханство», Хобон «Кубань», Барасу «Персия», Борус «Пруссия», Тюрюк «Турция» и др.; 4) названия народов: ермели «армяне», ештек «башкиры», хазак «кайсаки», хара халбакки «каракалпаки», хазал баши «персы», шибед «шведы» и др.; 5) названия городов и местностей, где бывали калмыки: Азои «Азов», Антибока «г. Антиповка», Бароунаш «г. Воронеж», Деремед «г. Дербент», Хазан «г. Казань», Хазлар «г. Кизляр», Серкеш «г. Красный Яр», Москуу «Г. Москва», Оронбур «г. Оренбург», Бола таб «г. Полтава», Самар «г. Самара», Сангк петер бург «г. Санкт-Петербург», Шара тоу «г. Саратов», Синбир «г. Симбирск», Тобул «г. Тобольск», Ахаи «г. Царицын», Айидархан «г. Астрахань» и т. д. [11].

Письма калмыцких ханов и владельцев имеют не только историческую ценность, но и лингвистическую, которая объясняется тремя причинами. Во-первых, тем, что они написаны на старописьменном калмыцком языке. Этот момент, который мы постоянно подчеркиваем в своих работах, важен для изучения истории калмыцкого языка конкретного времени - эпохи Калмыцкого ханства в составе Российского государства. Во-вторых, тем, что эти калмыцкие письма (оригиналы) хранятся вместе с их русскими переводами, которые выполнялись практически «синхронно» русскими переводчиками XVIII в. по мере поступления этих документов в городские, губернские и правительственные канцелярии, где работали эти переводчики. Эти переводы, кстати, являются тоже новым источником по истории русской деловой письменности XVIII в., которые, как и калмыцкие письма-оригиналы, датированы, привязаны к определенной территории (Поволжье, Дон, Кавказ), отражают иерархию и социальный статус участников письменного диалога. Благодаря этим переводам мы имеем определенное представление о профессиональной «деятельности» переводчиков и толмачей, которые, переводя калмыцкие тексты на русский язык XVIII в., раскрывали значения конкретных калмыцких слов, употребленных в конкретных текстах. Главное, нам известны имена русских переводчиков, которых, по нашим подсчетам, насчитывается более тридцати. Особое место среди них занимает Василий Михайлович Бакунин. Как сообщает он сам, его служба началась в 1720 г., когда он был взят из Царицына в Астрахань и определен губернатором А. П. Волынским, сподвиж- 
ником Петра Первого, в качестве переводчика калмыцкого языка [2, с. 8]. В БУ РКНА отложились десятки русских переводов писем хана Аюки, ханши Дармы Балы, хана Черен Дондука, Шакур-ламы, нойонов Чагдоржаба и Доржи Назарова, влиятельных калмыцких владельцев, выполненных В. М. Бакуниным. Эти переводы ценны тем, что В.М. Бакунин был лично знаком со всеми калмыцкими ханами XVIII в. Он лично общался с ханом Аюкой в 1720-1724 гг., с ханом Черен Дондуком в 1720-1735 гг., с ханом Дондук Омбой в 1720-1741 гг. и с ханом Дондук Дашой в 1720-1761 гг. Его перу принадлежит первый исторический очерк о калмыцких ханах и владельцах XVIII в. [2]. В-третьих, калмыцкие деловые письма XVIII в. и их «синхронные» русские переводы представляют собой уникальный материал для изучения взаимодействия и взаимовлияния в историческом аспекте двух разнотипных языков - русского и калмыцкого.

В XVIII в. потребность в документах и информации у калмыков, как и у других народов, была такой же острой, как и сегодня. Одним из носителей информации у калмыков этого времени было письмо «бичиг», которое даже по современным оценкам является настоящим документом. Бичиг-письмо, фиксируя информацию, обеспечивало ее сохранность, накопление, передачу другим лицам и использование в разное время. В БУ РКНА хранятся разнообразные жанры бичиг, которые требуют специального изучения. Деловые письма калмыцких владельцев XVIII в. свидетельствуют о том, что калмыки осознавали себя составной частью России. Они говорят о включенности калмыцкого народа во все сферы жизни российского общества, как внутренние (экономическую, политическую, хозяйственную и культурную жизнь), так и внешние (участие в войнах против врагов Российского государства). Красной нитью через деловые письма калмыцких владельцев проходит мысль об укреплении единства с русским народом.

В зависимости от содержания можно выделить несколько типов деловых писем, которые отражают, к примеру: 1) государственную (воинскую) службу калмыков; 2) зарубежные связи калмыков; 3) хозяйственную деятельность; 4 торгово-экономические отношения и др. В лексическом аспекте эти деловые письма XVIII в. интересны тем, что в них встречаются такие калмыцкие слова, которые с позиций XXI в. считаются либо утраченными, либо подвергшимися заметным фонетическим, лексико-семантическим и грамматическим изменениям. Рассмотрим три примера, связанные а) с расширением и б) сужением семантики калмыцких слов, выявленные в процессе сравнения двух временных срезов калмыцкого языка: XVIII и XXI в.

Первый пример. Рассмотрим транслитерацию фрагмента письма-оригинала XVIII в., написанного на тодо бичиг: 01. Халимикгийин нойодуд кэсэг / 02. эд чиги илэгэбэ тэндэ $\boldsymbol{м} \boldsymbol{Y} \boldsymbol{ч} \boldsymbol{u}$ байиху хубцаасун баса бей тэрэ эд / 03. хубцасуни ширитэй байинай = зуура хазан сули камска болоод орусгэксэн / 04. балһусун ду төүни удуржи үзэкүни манду йэкэ боодог болху үлү байину [БУ РКНА. Ф.И-36, Оп. 1, Д. 35, Л. 1047 об.]. Перевод Д. А. Сусеевой: «Калмыцкие нойоны тоже послали несколько вещей, там есть прах [хана Аюки], есть одежда. Тот груз и одежда зашиты. По дороге, если в Казани и Соликамске, русских городах, этот (груз и одежду) распорют, то нам будет большая задержкка. Не так ли?». В этом фрагменте из письма Намки-гелюнга И. И. Бахметеву и В. П. Беклемишеву от 
8 декабря 1729 г., написанного им в связи с предстоящей его поездкой в Тибет для поминовения хана Аюки, нас интересуют два слова: үмүчи и боодог, которые за минувшие три столетия претерпели изменения. Слово Үмүчи в данном фрагменте имеет значение праx. В современном словаре калмыцкого языка такого слова нет, но есть тождественное ему по смыслу слово - үмсн «прах». Слово боодог в тексте письма употреблено в значении задержка. В современном словаре калмыцкого языка [12, с. 109] такого значения у этого слова нет.

Второй пример. В языке русских переводов калмыцких писем XVIII в. «отложились» многие слова и выражения, которые сегодня не употребляются в русской речи. Но когда-то такие слова «служили» тому, чтобы русские и калмыки понимали друг друга, способствовали их культурному сближению и экономическому сотрудничеству. В связи с этим большой интерес представляет собой одно из таких слов, а именно: русское слово «завезень». Сегодня это слово относится к числу историзмов, так как оно вышло из употребления. Но в XVIII в. это слово использовалось русскими переводчиками для перевода калмыцкого слова кермен. Так, например, ханша Дарма Бала в августе 1730 г. обратилась к В. П. Беклемишеву, полковнику, состоявшему на службе у Астраханского губернатора, с просьбой, чтобы тот ей срочно предоставил плавательные средства для переправы ее нутука (людей и скота) на луговую сторону Волги, а именно: кермен и онгоцо «лодка». В русском переводе XVIII в. письма ханши Дармы Балы калмыцкое слово кермен переведено как «завезень». И вот как оно представлено в русском переводе (сохраняются старая орфография и пунктуация): 01. Дарма Бала Василию Пахомовичу писмо дала 02. в писме дело я хочу переправитца 3-го на лу 03. говую сторону. Итого ради прошу мне по 04. жаловать завезень и лотокъ поболше при 05. шлите иот ея Императорскаго величества 06. иотовсехъ четурехъ сторонъ какие ведо 07. мости есть. Меня уведомъ. Посланецъ 08. Самтанъ. [БУ РКНА. Ф. И-36, оп. 1, д. 37, л. 685]. В XVIII-XIX вв. слово завезень, как отмечает Вл. Даль в своем известном словаре, это «плоскодонная лодка сажени на три, съ разсохою с кормы и съ носу, по которымъ ходитъ канатъ; род речного баркаса, который заводитъ и закидываеть якорь, когда судно идет завозомъ». Именно завозни использовались калмыцкими владельцами при переправе своих нутуков (людей и скота) через Волгу. В современном же калмыцком языке историческое слово кермен представлено как керм, которое имеет значение «naроход, судно» [Хальмг-орс толь 1977: 295]. То, что слово кермен раньше могло обозначать и такое речное судно, как завозень, сегодня современным калмыцким языком утрачено.

Третий пример. По калмыцким письмам и их русским переводам XVIII в. можно уточнить, что некоторые слова были заимствованы русскими не в XIX в., а раньше, в XVIII в. Например, в «Школьном этимологическом словаре русского языка» [13, с. 101] указано, что слово зурна заимствовано в XIX в. Однако это время, возможно, потребует уточнения, поскольку материалы БУ РКНА говорят о другом. Так, в БУ РКНА хранится оригинал письма Чагдоржаба, старшего сына хана Аюки, в адрес астраханского боярина М. И. Чирикова, в котором содержится интересующее нас слово зурна. Чагдоржаб в своем письме обращается с просьбой в Астрахань, чтобы ему в связи с приездом к хану Аюке китайского 
посольства прислали ряд необходимых музыкальных инструментов, в том числе зурныл. Обращение к российской администрации за зурнами говорит о том, что русские имели уже в то время в своем распоряжении эти музыкальные инструменты и пользовались ими. Поэтому упоминание этого слова в мартовском письме 1714 г. доказывает, что оно было известно русским задолго до XIX в., и, вероятнее всего, могло быть заимствовано даже не в XVIII в., а намного раньше. Вот то письмо Чагдоржаба, интересующее нас (письмо написано на тодо бичиг и здесь дается в транслитерации), где употреблено слово зурна: 01.Чагдор жаб би эндэ мэндү 02. айидар хани = байар махали илүүүчү 03. тенду мэнду бэйизэ = амуһоуланг ту хаани 04. элчи ирэнэй $=$ мингһан чэрик арбан тобтой 05. бишкоур зурана барапан орушийин наадун тоотойиги 06. илгэгтүн $=$ кэрмэн сарай хара үйилэ бодун 07. сайин тоотойиги илгэгтүн $=$ боодогчи айоуһар 08. күрүгөүл $=$ үгэ элчийин аманду $=09$. элчи лоузанг норбу табоула [БУ РКНА. Ф. И-36, Оп.1, Д. 2, Л. 35; март 1714 г.]. Следовательно, калмыцкие деловые письма могут уточнять время заимствования отдельных слов в русском языке.

В статье мы рассмотрели проблемы калмыцкого языкознания, ключом к решению которых могут стать архивные материалы, несущие богатейшую информацию о калмыцком языке XVIII в. Решение названных проблем может быть связано и с более тщательным изучением словаря И. Рамстедта «Kalmückisches Wörterbuch» [14]. В 1961-1965 гг., в годы работы в КНИЯЛИ [7, 1964:129-143], мы занимались переложением этого словаря на карточки, которые позже были использованы при составлении известного словаря «Хальмг-орс толь» (1977 г.).

\section{Заключение и выводы}

Первая мысль касается терминологии калмыцкого языкознания, вторая создания теоретических грамматик калмыцкого языка.

1. Что касается терминологии, то здесь пора наводить порядок. Если дальше будут игнорироваться вопросы терминологии, то будут появляться методологические и методические ошибки. Во-первых, необходимо решить окончательно вопрос о том, что мы изучаем: «калмыцкий язык» или «ойратский язык», «калмыцкий письменный язык» или «ойратский письменный язык». Дело в том, что некоторые исследователи калмыцкого языка до настоящего времени употребляют эти термины, не уточняя их значение. Так, например, Н. О. Кокшаева считает, что есть «калмыцкий язык» и есть «ойратский письменный язык», которым, по ее мнению, написано «эпистолярное наследие калмыцкого хана Дондук-Даши» [4, с. 11-12]. Но другие лингвисты считают, что калмыки пользовались «калмыцким письмом», например Вл. Котвич [5]. Следовательно, необходимо уточнить такие понятия, как «калмыцкий язык» и «ойратский язык», «калмыцкий письменный язык / калмыцкое письмо» и «ойратский письменный язык», чтобы правильно употреблять их в исследованиях по калмыцкому языку. Во-вторых, если мы изучаем калмыцкий язык, то надо уточнить историю калмыцкого языка, этапы его развития и определить границы современного калмыцкого языка. Аргументированных ответов на эти вопросы пока нет. В-третьих, в зависимости от решения первых двух вопросов будет решаться вопрос об источниках калмыцкого языка на каждом этапе его развития. Вопрос этот серьезный, поскольку, например, не- 
которые языковеды-лингвисты сегодня считают, что не следует изучать язык произведений советских писателей, поскольку он идеологизирован. Но, как известно, язык, будучи связанным с эпохой своего функционирования, обязательно отражает эту эпоху и ее идеологию. Поэтому отказываться от языка текстов советской эпохи при изучении современного калмыцкого языка так же неразумно, как неразумно отказываться от языка текстов XVII-XIX вв., как языка, обслуживавшего в свое время феодальное и капиталистическое общества и их идеологию. В-четвертых, необходимо четко различать диахронический и синхронный аспекты, статику и динамику калмыцкого языка. Неразличение этих аспектов калмыцкого языка приводит к смешению понятий «синхронное состояние языка» и «история развития калмыцкого языка», а также процессов, наблюдаемых в синхронном состоянии языка: динамики и статики. В качестве примера неточности использования терминов можно привести работу Н. О. Кокшаевой [4], которая, по существу, посвящена языковым особенностям официально-деловых писем калмыцкого хана Дондук-Даши, а не языковым особенностям его «эпистолярного наследия», как сообщается в заголовке книги. К сожалению, в этой работе большое внимание уделяется экскурсам в область истории ойратского и монгольского языков [4, с. 11-43] и приводятся многочисленные примеры сопоставительного характера типа: ойр. хоуоr duulха, стп.-м. хоуоr durulara, халха-монг. хоер хуяг дуулга, калм. хойр дуулх «два шлема, две каски» и т. п. [4, с. 54 и др.]. Большую часть этой работы составляет не синхронное описание особенностей языка конкретного времени - середины XVIII в., как заявлено заголовком самой работы, а история других монгольских языков и вопросы их сопоставления. И, к сожалению, совсем не освещаются динамические и статические признаки языка официально-деловых писем Дондук-Даши.

2. Вторая мысль касается создания теоретической грамматики современного калмыцкого языка. Во-первых, пора написать научную грамматику современного калмыцкого языка, где будут описаны все уровни языковой системы (фонология, морфемика, словообразование, лексикология, морфология, синтаксис) с учетом тех достижений, которые имеет современная наука о языке - лингвистика. Только такая грамматика станет надежной базой для создания всех типов современных грамматик (вузовской, школьных, нормативных, коммуникативных), а также разных типов словарей современного калмыцкого языка. Во-вторых, надо написать и полную историческую грамматику калмыцкого языка XVIII в., где будут описаны все уровни языковой системы в историческом аспекте, которая станет базой для составления всех типов словарей исторического характера (этимологического, словаря официально-делового языка XVIII в. и др.). В-третьих, надо, наконец, осознать всем исследователям калмыцкого языка, без исключения, что только тщательно выполненная работа, предлагаемая выше, позволит уточнить всю терминологию, которая используется сегодня исследователями калмыцкого языка, систематизировать и привести ее в соответствие с терминологией, принятой в современной лингвистике. Другого способа уточнить и усовершенствовать лингвистическую терминологию нет. Попытки создать сначала новую калмыцкую терминологию, а затем только заниматься исследованием и созданием калмыцких грамматик и словарей - это профанация. Правильный 
путь: терминология создается, уточняется и совершенствуется только в процессе исследования конкретных языковых фактов, аспектов, уровней, систем и их единиц, а также функций языка.

Как нам представляется, важные проблемы современного калмыцкого языкознания могут быть решены только при условии привлечения исторического (архивного) материала. В связи с этим необходимо направить усилия ученых на создание исторической грамматики и исторического словаря калмыцкого языка.

\section{Источники}

БУ РКНА - Бюджетное учреждение Республики Калмыкия «Национальный архив» БУ РКНА. Ф. И-36. Оп.1. Д. 35. Л. 1047 об.

БУ РКНА. Ф. И-36. Оп.1. Д. 37. Л. 685.

БУ РКНА. Ф. И- 36. Оп.1. Д. 2. Л. 35; март 1714 г.

\section{Литература}

1. Асирова Н. Д. Исследование частей речи в калмыцком языке XVIII века (на материале деловых документов): автореф. дис. ... канд. филол. наук. М., 2002. 25 с.

2. Бакунин В. М. Описание калмыцких народов, а особливо из них торгоутского, и поступков их ханов и владельцев. Сочинение 1761 года. Элиста: Калмыцкое книжное издательство, 1995. 153 с.

3. Гедеева Д. Б. Письма наместника Калмыцкого ханства Убаши (XVIII в.). Элиста: Изд-во КИГИРАН, 2004. 194 с.

4. Кокшаева Н. О. Языковые особенности эпистолярного наследия калмыцкого хана Дондук-Даши. Элиста: Герел, 2011. 191 с. $418 \mathrm{c}$.

5. Котвич Вл. Л. Опыт грамматики калмыцкого разговорного языка. Прага, 1929.

6. Очерки истории Калмыцкой АССР. Дооктябрьский период / под ред. Н. В. Устюгова. М.: Наука, 1967. 479 с.

7. Сусеева Д. А. Ramstedt G. I. Kalmückisches Wörterbuch. Helsinki, 1935 // Записки КНИИЯЛИ. Элиста: Калмиздат, 1964. Вып. 3. С. 129-143.

8. Сусеева Д. А. Письма хана Аюки и его современников (1714-1724 гг.): опыт лингвосоциологического исследования. Элиста, 2003. 459 с.

9. Сусеева Д. А. Письма калмыцких ханов XVIII века и их современников (17131771 гг.). Избранное // Грамматический строй калмыцкого языка XVIII века: морфонология и морфология (на материале писем калмыцких ханов и их современников). Элиста, 2011. $199 \mathrm{c}$.

10. Русские переводы XVIII века деловых писем калмыцких ханов и их современников: тексты и исследования / Д. А. Сусеева [и др.]. М.. Элиста, 2013. 743 с.

11. Хараева А. Т. Русские заимствованные слова в калмыцком языке XVIII века. Элиста: Калмыцкий государственный университет, 2014. 223 с.

12. Хальмг-орс толь / под ред. Б. Д. Муниева. М.: Русский язык, 1977. 764 с.

13. Шанский Н. М., Боброва Т. А. Школьный этимологический словарь русского языка. Происхождение слов. М.: Дрофа, 2000. 399 с.

14. Ramatedt G. J. Kalmückisches Wörterbuch. Helsinki, 1935. 


\title{
ARCHIVAL MATERIALS AND PROBLEMS OF KALMYK LINGUISTICS
}

\author{
Danara A. Suseeva \\ Dr. Sci. (Phil.), Prof., Prof. of Department of Russian Language and General Linguistics, \\ Russian and Foreign Literature, \\ Gorodovikov Kalmyk State University \\ 11 Pushkina St., Elista 358000, Russian Federation \\ suseeva@gmail.com
}

Abstract. The municipal institution of Republic of Kalmykia "National Archive" is home to archive materials that can be of great help to a modern researcher-kalmykologist. Thousands of Kalmyk khans business letters written in XVIII century and their contemporaries brought to us not only the history of specific events in the past, but also a cultural (conceptual) picture of the Kalmyk people world, which was formed on the basis of specific people and has been received with the help of senses of those people and passed through their consciousness, both collective and individual. These archival materials show that the cultural picture of Kalmyk people world is rich and unique. This peculiarity is associated with a number of facts, namely: the nomadic way of life of the people, culture, history, social structure of society, religion, traditions, customs in the new sociohistorical conditions. Exploring the world of Kalmyks in XVII-XVIII centuries, their culture, way of life, national character, mentality, provides the opportunity to get to know the features of Kalmyk language, because the real use of the Kalmyk words in speech, the real Kalmyk speech activity (or reciprocate) is largely determined by social and cultural life of Kalmyk language speaker, the language of s Kalmyk people within the Russian state for over 400 years. Kalmyk language structures are based not only on socio-cultural structures, but also on speech structures. Knowing the meaning of Kalmyk words and the rules of Kalmyk grammar is not enough to use the language as a means of communication, making this communication effective and efficient. There is need to know more about the world of the language you are learning. When studying speech activity, it is necessary to pay attention to who, when, where, to whom, what was said/written, how the content (information) said/written corresponds to the reality in which communication is carried out. The language of business correspondence between Kalmyk khans and their contemporaries provides answers to many problematic questions of Kalmyk linguistics and, in particular, Kalmyk lexicography.

Keywords: Kalmyk language of the XVIII century; material, methodology, and method research; archival documents as a basis for solving historical problems lexicographies.

Статья поступила в редакиию 26.10.2020; одобрена после рецензирования 13.11.2020; принята к публикациии 01.12.2020. 